\title{
Cambio climático y su impacto sobre la salud humana
}

\author{
Climate change and its impact on human health
}

\author{
Patrizio Petrone $\mathbb{D}$
}

Coeditor, Revista Colombiana de Cirugía; Associate Professor of Surgery, NYU Long Island School of Medicine; Director of Surgical Research, Program Director of the International Research Fellowship, Department of Surgery, NYU Langone Health - NYU Winthrop Hospital; New York - USA

El "Panel intergubernamental sobre el cambio climático" de las Naciones Unidas (Intergovernmental Panel on Climate Change, IPCC), el máximo organismo científico mundial sobre el tema, publicó IPCC, 20I8: Global Warming of $1.5^{\circ} \mathrm{C}^{\mathrm{I}}$. Más de 90 científicos de 40 países que revisaron 6.000 estudios prepararon el informe del IPCC en respuesta a una solicitud del acuerdo climático de París en 2015.

Su propósito era discriminar entre los efectos del calentamiento global a $1,5^{\circ} \mathrm{C}\left(2,7^{\circ} \mathrm{F}\right)$ versus 2,0 ${ }^{\circ} \mathrm{C}\left(3,6^{\circ} \mathrm{F}\right)$. El acuerdo de París requería mantener el calentamiento por debajo de $2,0^{\circ} \mathrm{C}$ mientras se realizan esfuerzos para limitarlo a $\mathrm{I}, 5^{\circ} \mathrm{C}$. De este modo, si las temperaturas aumentan en I,5 ${ }^{\circ} \mathrm{C}$, el informe reportó que de 105.000 especies estudiadas, el $4 \%$ de los vertebrados, el $6 \%$ de los insectos y el $8 \%$ de las plantas perderían la mitad de su rango geográfico determinado por el clima. Con un aumento de $2,0^{\circ} \mathrm{C}$, estos porcentajes se duplicarían y hasta triplicarían en algunos casos.
Con un aumento de $\mathrm{I}, 5^{\circ} \mathrm{C}$, perderíamos entre el 70 y el $90 \%$ de los arrecifes de coral, mientras que con $2,0^{\circ} \mathrm{C}$ la pérdida sería de $99 \%$.

Según estos informes, la tierra se ha calentado I ${ }^{\circ} \mathrm{C}$ desde la era preindustrial, y dos tercios de este aumento se ha producido desde 1986. Los veinte años más cálidos registrados se han producido en los últimos 22 años, principalmente debido al aumento de la temperatura de los océanos, que fueron sorprendentemente cálidos en 2017. Superaron a 2015, el segundo año de temperatura del océano más cálido, por I,5I x IO $\wedge 22$ julios, es decir, la cantidad de energía eléctrica que produce anualmente China. Entre otros resultados estrepitosos del calentamiento del océano se encuentra la acidificación, particularmente problemática para el fitoplancton que produce la mitad del oxígeno que respiramos.

En cuanto a la causa del calentamiento global, o la relación casi lineal entre las emisiones de gases de efecto invernadero y el calentamiento

Palabras clave: calentamiento global; efecto invernadero; salud mundial; efectos.

Key words: global warming; greenhouse effect; global health; effects.

Fecha de recibido: 07/03/2020 - Fecha de aceptación: 27/03/2020 - Fecha de actualización: 17/07/2020

Correspondencia: Patrizio Petrone, MD, PhD, MPH, MHSA, FACS, Department of Surgery, NYU Winthrop Hospital; 222 Station Plaza

North, Suite 300; Mineola, New York, 11501, USA. Teléfono: +1 (516) 663-9571

patrizio.petrone@gmail.com y patrizio.petrone@nyulangone.org

Citar como: Petrone P. Cambio climático y su impacto sobre la salud humana. Rev Colomb Cir. 2020;35:347-50.

https://doi.org/10.30944/20117582.723

Este es un artículo de acceso abierto bajo una Licencia Creative Commons - BY-NC-ND https://creativecommons.org/licenses/by-ncnd/4.0/deed.es 
atmosférico, más de 42.000 millones de toneladas de contaminación de efecto invernadero se descargan en la atmósfera cada año en todo el mundo, cantidad que sigue en aumento. Según el Proyecto Global de Carbono, se espera que sus emisiones aumenten $2,7 \%$ anualmente, en parte debido a los aumentos consecutivos en el consumo de petróleo.

El aire más caliente retiene más agua y las temperaturas más elevadas causan una mayor evaporación de la superficie; a su vez esto aumenta el número y la gravedad de los eventos de lluvia, ahora denominados bombas de lluvia, lo que provoca la intensidad, frecuencia y duración de los huracanes. La devastación causada por el huracán Harvey, en parte fue el resultado de las temperaturas de la superficie del golfo de México que por primera vez no se ubicaron por debajo de $23^{\circ} \mathrm{C}$. El huracán María, en 20I7, causó casi 3.000 muertes en un Puerto Rico diezmado ${ }^{2}$. Económicamente, Harvey, Irma y María juntos, causaron más de 300.000 millones de dólares en daños. En una investigación reciente publicada en Nature, se concluyó que el calentamiento global hará que los huracanes se vuelvan aún más mortales al intensificar las precipitaciones hasta en Io \% y las velocidades del viento en $40 \mathrm{~km} /$ hora $^{3}$.

Más allá de la gravedad creciente de los huracanes, el calentamiento global significa que la tasa actual de aumento en el nivel medio global del mar es mayor que en cualquier otro momento de la historia. Como ejemplo, si las capas de hielo de Groenlandia se descongelaran, agregarían 6 metros a la altura de todos los mares, mientras que el deshielo de la capa superior de la Antártida occidental agregaría otros 3 metros ${ }^{4}$. Para ponerlo en perspectiva, a 6 metros, la mayor parte de Florida y un tercio de la ciudad de Nueva York estarían bajo el agua. Se debe tener en cuenta que 145 millones de personas en todo el mundo viven a un metro o menos sobre el nivel del mar y que el io \% de la población mundial, casi 800 millones, viven a menos de 9 metros del nivel actual del mar 5 . Once de las 16 megaciudades, consideradas como tales a aquellas con más de I5 millones de habitantes, están construidas en las costas; entre ellas se encuentran Yakarta, Los Angeles, Manila, Mumbai, Osaka, Shanghai y Tokio.

Los mares crecientes y las inundaciones también comprometen el agua potable, el tratamiento de aguas residuales humanas y la eliminación de aguas pluviales, lo cual a su vez aumenta el riesgo de enfermedades transmisibles causadas por agentes patógenos (bacterias, virus y protozoos). Entre I 948 y I994, el $68 \%$ de los brotes en los Estados Unidos fueron por enfermedades transmitidas por el agua ${ }^{6}$. Las tormentas graves también significan una mayor contaminación de los alimentos mediante el aumento del transporte de agentes patógenos como la salmonela. Por lo tanto, el calentamiento global influye en el destino, transporte, transmisión, viabilidad y tasa de multiplicación de agentes patógenos en la cadena alimentaria.

El calor y la sequía aumentan la prevalencia, intensidad y duración de los incendios forestales. Los recientes incendios de California, los más letales de la historia de ese estado, en parte fueron el resultado de haber experimentado cinco años consecutivos de calor sin precedentes, lluvias en 2018 al $20 \%$ de la norma histórica y la peor sequía en un milenio ${ }^{7}$. La cantidad de carbono que pueden emitir estos incendios puede ser masiva, lo que exacerba aún más las tendencias generales del cambio climático. Se estima que los incendios forestales y de turba en Indonesia durante 1997 liberaron más del $40 \%$ del total anual de emisiones de carbono a nivel mundial. Tales incendios también tienen un impacto duradero en la calidad del aire, con graves consecuencias para la salud. Para 2050, se anticipa que los incendios forestales darán como resultado un aumento de $40 \%$ en el carbono orgánico y de $20 \%$ en las concentraciones de carbono en aerosol.

El calor, la sequía y los incendios forestales también contribuyen al empeoramiento de la contaminación y al aumento de los niveles de aeroalérgenos como el polen. Combinados, estos son responsables de decenas de miles de episodios de enfermedad respiratoria aguda que conducirán a muertes prematuras e ingresos 
hospitalarios. En 20I3, el año del airpocalypse de China, los investigadores encontraron que, en las 74 ciudades chinas más importantes, la contaminación del aire se asoció aproximadamente con un tercio de las muertes ${ }^{8}$.

Las temperaturas más altas causan agotamiento por calor, insolación, hipertermia y deshidratación que en casos extremos pueden ser fatales. Además, pueden empeorar las condiciones médicas preexistentes, como hipertensión arterial sistémica, y enfermedades cardiovasculares, respiratorias, cerebrovasculares, renales y las relacionadas con la diabetes. Es difícil calcular la morbilidad y la mortalidad debidas al calor extremo, ya que los registros médicos rara vez capturan datos que se relacionen entre sí. Sumado a ello, las temperaturas más cálidas del invierno y la primavera significan el inicio anual más temprano de los casos de enfermedad de Lyme. Las temperaturas más elevadas contribuyen a las enfermedades transmitidas por vectores (mosquitos, pulgas, garrapatas y roedores). Las temperaturas más cálidas, por ejemplo, aceleran el ciclo reproductivo de los mosquitos de sangre fría, haciendo que los casos de fiebre del dengue se dupliquen cada década desde 1990.

La alteración climática también causa una larga lista de afecciones de salud mental y conductual que van desde ansiedad, depresión y abuso de alcohol y otras sustancias, hasta estrés postraumático y suicidio. Después del huracán Katrina en 2005, los veteranos con enfermedades mentales preexistentes tenían un riesgo casi siete veces mayor de desarrollar una enfermedad mental adicional. Los intentos de suicidio después de ese huracán entre las mujeres que vivían en viviendas temporales, aumentaron 15 veces en comparación con los promedios regionales, y la incidencia de delitos violentos, incluidos los homicidios y la violencia contra las mujeres, aumentó sustancialmente.

Mientras la economía mundial se defina en gran medida como el capitalismo fosilizado, las extinciones masivas o la pérdida de diversidad filogenética continuarán. Entre otras cosas, también continuaremos viendo pérdidas considerables en la pesca mundial y el colapso de las poblaciones de insectos ${ }^{9}$. Esto último contribuirá a un profundo efecto negativo en la producción de alimentos. De hecho, 30 países están experimentando actualmente cosechas negativas y hay una probabilidad de calor de uno en veinte, lo cual afecta sobre todo la cosecha de maíz.

Dejando de lado la producción, vale la pena señalar que las concentraciones más altas de $\mathrm{CO}_{2}$ en el aire estimulan la producción de carbohidratos, almidón y azúcares, y el crecimiento en varios cultivos ampliamente consumidos, como la cebada, la papa, el arroz y el trigo. También reduce el nivel de proteína vegetal hasta en $15 \%$. El aumento del $\mathrm{CO}_{2}$ atmosférico también agota el calcio, el cobre, el hierro, el magnesio, el cinc y otros minerales en la mayoría de las plantas en más de io \%, debido a que las concentraciones más altas de $\mathrm{CO}_{2}$ reducen la demanda de agua de ellas, lo que hace que se absorban menos nutrientes en sus raíces. Estos factores en su conjunto, a su vez también podrían contribuir a mayores tasas de obesidad.

Existe una serie de consecuencias adicionales o en cascada relacionadas con el cambio climático, que afectan desproporcionadamente a mujeres embarazadas, niños, ancianos y discapacitados, minorías y pobres. La vulnerabilidad es una función de la sensibilidad al cambio y la capacidad de adaptación al mismo. Los ancianos son particularmente vulnerables, ya que con frecuencia están inmunocomprometidos, se les recetan ciertos medicamentos que limitan la termorregulación o bloquean los impulsos nerviosos, y un porcentaje significativo tiene un deterioro cognitivo o está socialmente aislado. No es de sorprender que la mitad de las muertes por Katrina fuera de personas mayores de 75 años y la mortalidad afroamericana fuera de dos a cuatro veces mayor que la de caucásicos. Debe tenerse en cuenta que la población estadounidense de 65 años o más casi se duplicará de 48 a 88 millones entre el período del 2015 al 2050.

Si bien la salud siempre ha sido afectada por el clima, es el cambio en su variabilidad lo que constituye una amenaza significativa para la salud humana. La industria de la atención en salud, el segundo mayor contaminante de gases 
de efecto invernadero después de la industria alimentaria, que representa casi el io \% de la contaminación ${ }^{\mathrm{I}}$, y supuestamente dedicada a prevenir y tratar las enfermedades causadas o exacerbadas por el calentamiento global, sigue siendo en gran medida indiferente.

Al momento de finalizar este artículo la humanidad está siendo azotada por la pandemia de COVID-I9 producida por el virus denominado SARS-CoV-2. Respecto de su origen siguen predominando dos teorías: mientras una indica que el virus provendría de los murciélagos, que tuvo un paso intermedio en el pangolín (mamífero que se halla en peligro de extinción), y que tras su ingestión se transmitió al hombre, siendo el epicentro un mercado de animales vivos para consumo humano en la ciudad de Wuhan, China, hacia finales de 2019, la otra teoría apunta a un centro de virología ubicado en sus cercanías. Sea como fuere su origen, lo cierto es que el mundo no solo se ha conmovido desde el punto de vista sanitario, sobrepasando largamente los I6,2 millones de casos confirmados y más de 648.000 personas fallecidas al día de finalizar el presente artículo ", sino también causando una enorme disrupción socioeconómica y psicológica.

Luego de varios meses de detectado el primer caso, aún persisten más preguntas que respuestas. Si bien el COVID-I9 ha cambiado la vida de millones de personas, no va a terminar con la humanidad, pero se debe reaccionar y tomar como un llamado de alarma y atención que incentive a reflexionar sobre cómo nuestras acciones afectan el ecosistema en el que vivimos. Seguramente esta no será la última pandemia y vendrán otras enfermedades, pero si no se aprende la lección y se continúa teniendo el mismo impacto negativo en la naturaleza, tal vez en el futuro el planeta no sea tan benevolente con nuestra especie como lo ha sido hasta ahora.

\section{Cumplimiento de normas éticas}

Consentimiento informado: Este artículo es el resultado de una revisión de la literatura, y como tal no hay necesidad de un consentimiento informado ni de aprobación del Comité de Ética Institucional.
Declaración de conflicto de intereses: El autor declara que no tiene conflictos de intereses.

Fuentes de financiación: Recursos propios del autor.

\section{Referencias}

I. Masson-Delmotte V, Zhai P, Pörtner HO, Roberts D, Skea J, Shukla PR, et al. (Eds.). IPCC, 2018: Global Warming of $1.5^{\circ} \mathrm{C}$. An IPCC Special Report on the impacts of global warming of $1.5^{\circ} \mathrm{C}$ above pre-industrial levels and related global greenhouse gas emission pathways, in the context of strengthening the global response to the threat of climate change, sustainable development, and efforts to eradicate poverty. Geneva: World Meteorological Organization; 2018.

2. Santos-Lozada AR. In Puerto Rico, counting deaths and making deaths count. Health Affairs. 20I8;37:520-2. https://doi.org/IO.I377/hlthaff.2018.0219

3. Patricola CM, Wehner MF. Anthropogenic influences on major tropical cyclone events. Nature. 2018;563:33946. https://doi.org/IO.I038/s4I586-0I8-0673-2

4. Graeter KA, Osterberg EC, Ferris DG, Hawley RL, Marshall HP, Lewis G, et al. Ice core records of West Greenland melt and climate forcing. Geophysical Research Letters. 2018;45:3164-72.

https://doi.org/IO.IO02/20I7GLo7664I

5. McGranahan G, Balk D, Anderson B. The rising tide: Assessing the risks of climate change ad human settlements in low elevation coastal zones. Environment and Urbanization. 2007;19:17-37.

6. Basu R, English P, Knowlton K, Romero-Lankao P, Ostro B, Semenza J, et al. (Eds.). The impacts of climate change on human health in the United States: A scientific assessment. Washington, DC: U.S. Global Change Research Program; 2016.

7. Indicators of Climate Change in California. Office of Environmental Health Hazard Assessment, California Environmental Protection Agency; 2018.

8. Fang D, Wang Q, Li H, Yu Y, Lu Y, Qian X. Mortality effects assessment of ambient $\mathrm{PM}_{2.5}$ pollution in the 74 leading cities of China. Sci Total Environ. 2016;56970:I545-52.

9. Jarvis B. The insect apocalypse is here: What does it mean for the rest of life on Earth? The New York Times Magazine, New York, 2018.

Io. Eckelman MJ, Sherman J. Environmental impacts of the U.S. health care system and effects on public health. PLoS ONE. 20I6;II:eoI570I4. https://doi.org/IO.I37I/journal.pone.oI570I4

II. Johns Hopkins University. Coronavirus Resource Center. Fecha de consulta: 27 de julio de 2020. Disponible en: https://coronavirus.jhu.edu/map.html 